\title{
Surgical Resection of Retroperitoneal Aggressive Angiomyxoma: Case Report and Review of the Literature
}

\author{
Mircea Beuran ${ }^{1}$, Cezar Ciubotaru ${ }^{2}$, Alexandru Runcanu ${ }^{1}$, Valentin Enache ${ }^{3}$, Ionut Negoi ${ }^{1}$ \\ 1. Department of General Surgery, Emergency Hospital of Bucharest, Romania 2. CH Iii, Emergency \\ Hospital of Bucharest, Romania 3. Pathology Department, Emergency Hospital of Bucharest, Romania
}

$\square$ Corresponding author: Ionut Negoi, negoiionut@gmail.com

Disclosures can be found in Additional Information at the end of the article

\section{Abstract}

Aggressive angiomyxoma is a benign stromal tumor with a higher prevalence in middle-aged women. The objective of this case report is to illustrate the aggressive clinical behavior of this benign tumor. We present the case of a 45-year-old female patient, with tumor recurrence after multiple surgical resections of a pelvis-subperitoneal angiomyxoma. Surgical excision of the tumor, with extensive pelvic dissection and organ resection, was performed. The 12-month follow-up showed no tumor recurrence. Based on this case, and the published literature we may conclude that surgical resection represents the main treatment of aggressive angiomyxoma, even though it is associated with significant morbidity and a poor local control of the tumor.

Categories: Obstetrics/Gynecology, General Surgery, Oncology

Keywords: aggressive angiomyxoma, soft tissue tumor, surgical resection

\section{Introduction And Background}

Angiomyxoma is a soft tissue neoplasia [1], with the highest prevalence in young white middleaged women [2]. It is a rare tumor, with a slow growth rate, and despite property to invade adjacent structures, the metastasis rate is low [3]. Although described for the first time by Virchow in 1883 as soft tissue myxomata, fewer than 350 cases of aggressive angiomyxoma were published in the medical literature [4]. The most important clinical feature of this type of tumor is the high local recurrence rate [5]. On pathology examination, the vascular structures are well represented, and differential diagnosis with other myxoid tumors is difficult [6]. The surgical approach should be the first step of treatment in this type of disease [7]. The aim of this case report is to reveal the aggressive clinical behavior of this benign tumor. We obtained the patient's informed consent for publication.

Received 06/16/2017 Review began 07/03/2017 Review ended 07/09/2017 Published 07/18/2017

\section{(c) Copyright 2017}

Beuran et al. This is an open access article distributed under the terms of the Creative Commons Attribution License CC-BY 3.0., which permits unrestricted use, distribution, and reproduction in any medium, provided the original author and source are credited.

\section{Review}

\section{Case report}

A 45-year-old woman, with multiple surgical resections (2007, 2009, 2010, and 2014 - tumor resection and left oophorectomy) of a pelvis-subperitoneal angiomyxoma, was referred to our hospital one year after the latest surgical procedure for a tumor recurrence.

On clinical examination, a large tumor could be palpated into the hypogastrium, with a bulging in the right gluteal and ischioanal areas in standing position. A $3 / 3 \mathrm{~cm}$ elastic tumor bulged into the right femoral area. The pelvic magnetic resonance imaging (MRI) revealed a well- 


\section{Cureus}

circumscribed tumor located into the right pararectal, parametrial, paravaginal, and iliac areas, with extension medial to the femoral vein into the femoral area; inhomogeneous with the presence of solid and fluid density areas; without lymph node involvement.

Total hysterectomy with bilateral oophorectomy, wedge rectal resection, and four centimeters of the right pelvic ureter resection was performed (Figure 1). 


\section{Cureus}

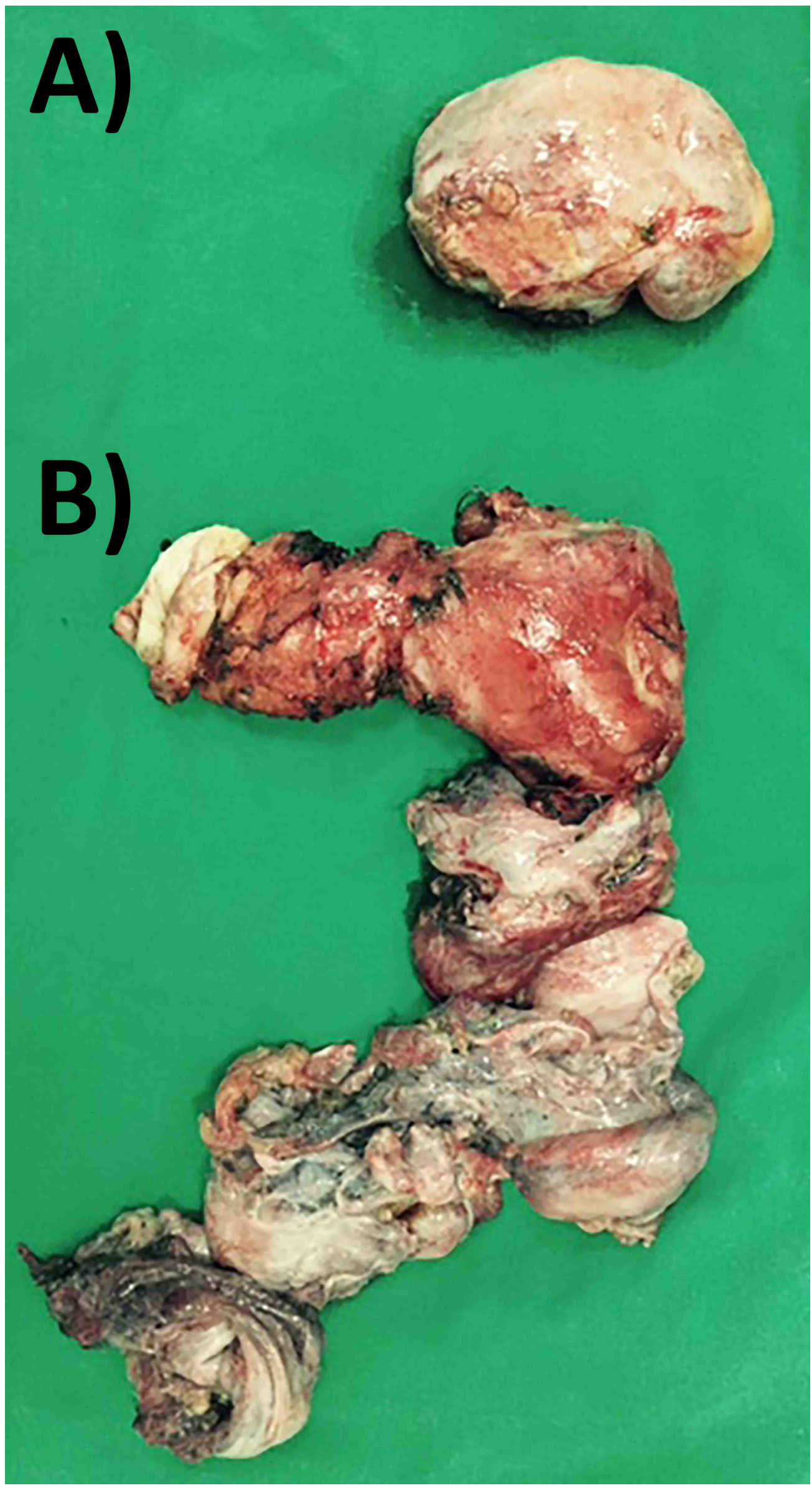

FIGURE 1: Resection specimen, including the left ovary (A) and 
recurrent tumor, uterus and both adnexa, and a 3-cm segment of the right ureter (B).

Postoperative evolution was favorable, without postoperative complications, with discharge on postoperative day 11 . Two months later, synchronous with right ureter stent removal, tumor extension into the right femoral area was resected, with no complications.

\section{The 12-month follow-up showed no tumor recurrence}

Histopathological examination revealed aggressive angiomyxoma with estrogen receptors positivity in $75 \%$ of the tumor cells, progesterone receptors in $80 \%$ of the tumor cells, actin and CD34 positivity in blood vessels, desmin positivity, and Ki67 positivity in 3\% of the cells (Figure 2).

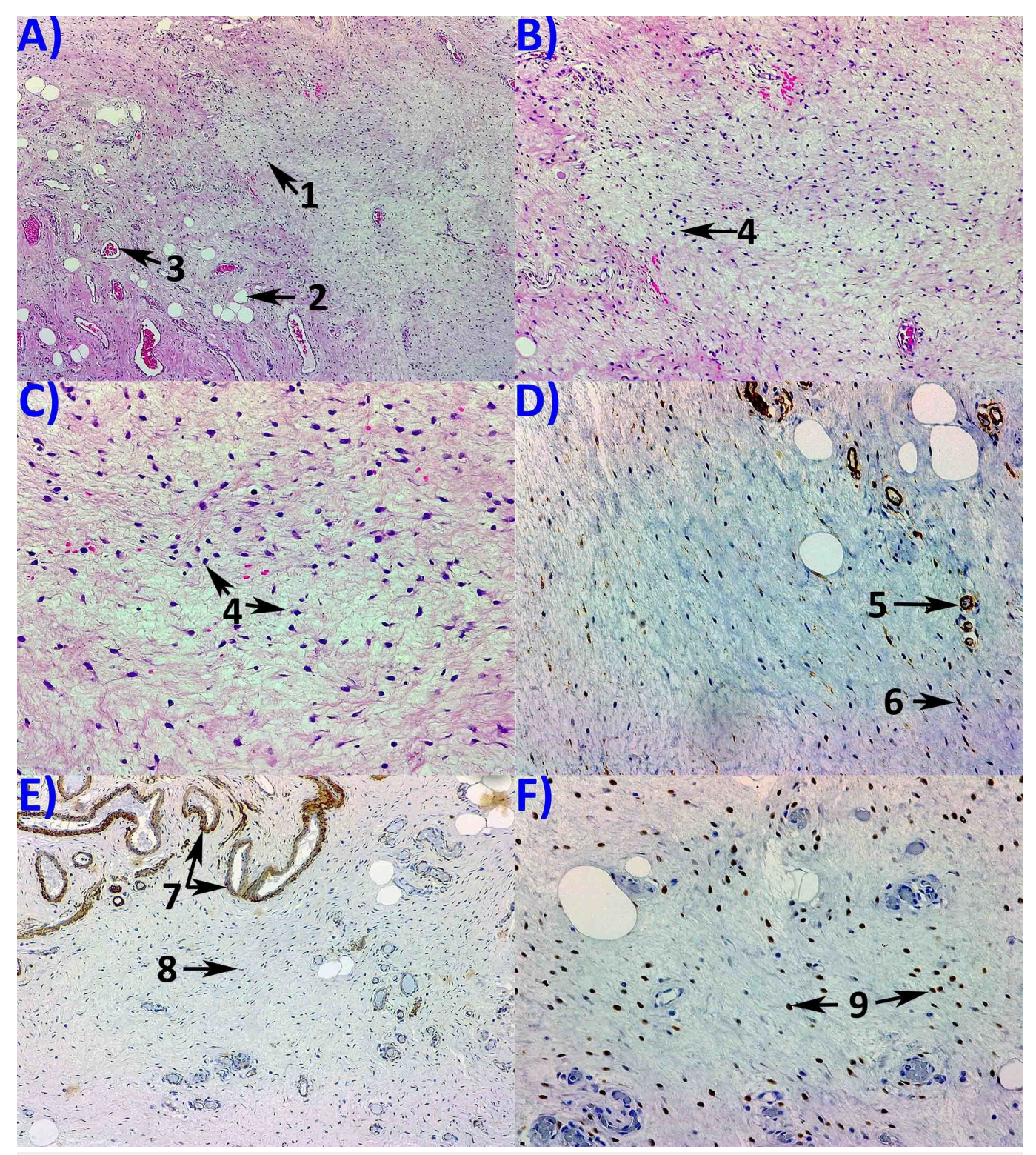

FIGURE 2: Pathology examination. (A) Hematoxylin and Eosin staining using $50 \mathrm{x}$ objective revealing tumor proliferation with 
scarce tumor cells (1); adipocytes (2) and blood vessels (3) can be observed; no tumor necrosis is seen. Hematoxylin and Eosin staining using 100x (B) and 200x (C) objectives, showing fusiform and stellate cells (4) with low mitotic activity, with abundant stroma. Immunohistochemistry expression using $200 x$ objective revealing of CD 34 positivity in the tumor cells (5) and blood vessels (6) (D); 100x objective revealing musclespecific actin (MSA) positivity in the muscular layer of blood vessels (7) but negative in the tumor cells (8) (E); 200x objective revealing ER positivity in the tumor cells (F).

Review of the literature (Figure 3).

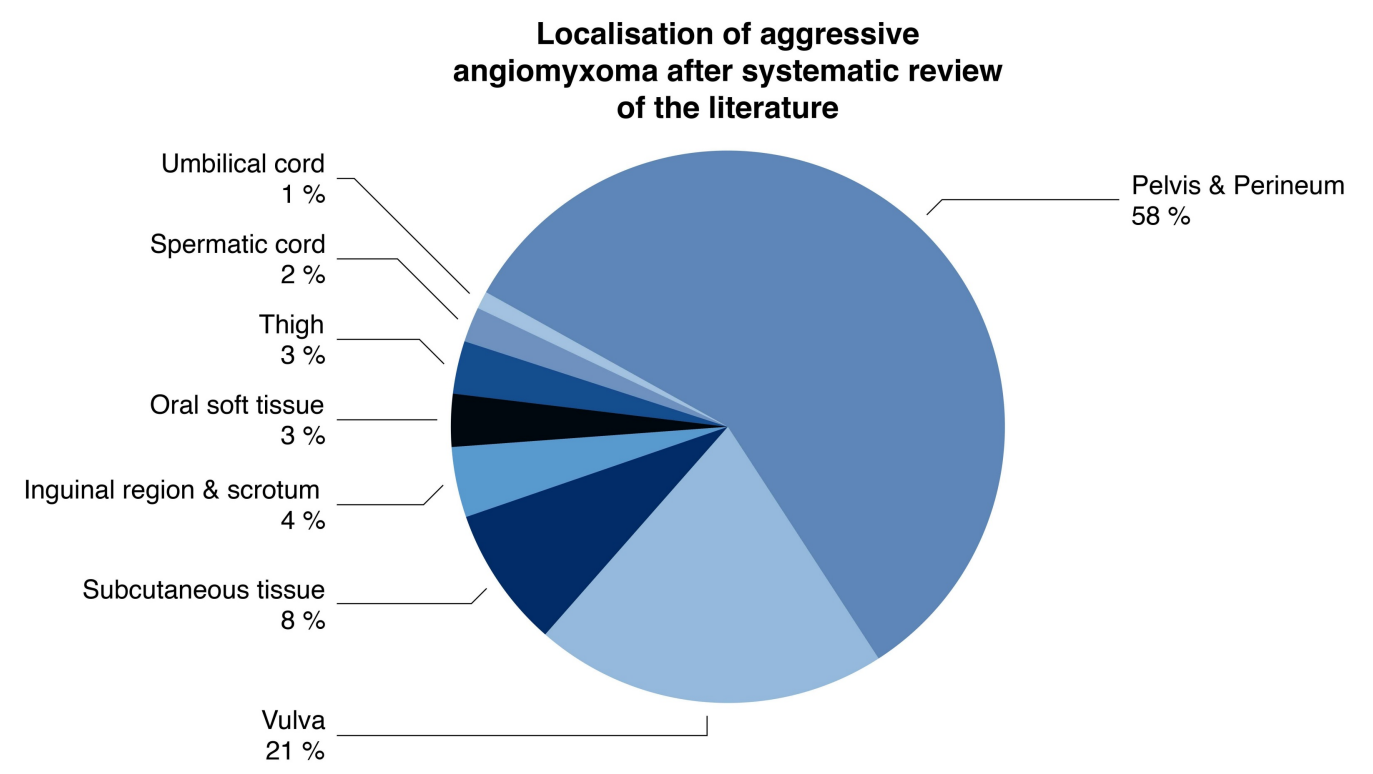

FIGURE 3: Localization of aggressive angiomyxoma according to the peer-reviewed literature.

\section{Discussions}

Steeper and Rosai coined this tumar as aggressive angiomyxoma, the distinctive variant of myxoid neoplasm that occurred predominantly in female pelvic or perineal areas [8]. Although described in both gender, the prevalence of aggressive angiomyxoma is 6.6 higher in women compared to men [5]. Aggressive angiomyxoma is considered to be a low-grade sarcoma, with the property to recur locally [9]. Two cases of metastatic aggressive angiomyxoma were described [4].

The histological structure of aggressive angiomyxoma consists mainly in a bland myxoid and vascular stroma, without a capsule, being locally infiltrative. The tumor macroscopic aspect is 
similar to that of healthy tissue; therefore the complete surgical resection is difficult [10]. A primitive pluripotent cell located around the vessels of connective tissue was proposed as the origin of the aggressive angiomyxoma [11]. Overlapping immunohistochemical and ultrastructural features between vulvar angiomyxoma, aggressive angiomyxoma, and angiomyofibroblastoma were revealed [11]. Our patient had immunohistochemical similarities with ones showed by Alameda, et al., with CD34 positivity, and muscle-specific actin (MSA) negativity [11].

As the aggressive angiomyxoma usually develops during the fertile period and pregnancy, they are believed to have hormone receptors [12]. The current evidence shows the constant positivity of the tumor cells for estrogen and progesterone receptors [4]. In our case, the immunohistochemistry examination revealed estrogen and progesterone receptors positivity in $75 \%$ and $80 \%$ of the tumor cells, respectively.

The diagnosis of this type of tumor is usually difficult, due to clinical onset of unspecific symptoms; it consists in local pain, swelling, dyspareunia, bowel and urinary tract dysfunctions. The aggressive angiomyxomas present a characteristic pattern on MRI, with 'swirls' aspect of low-intensity internal stranding on T1- and T2-weighted images [13-15].

The main treatment of aggressive angiomyxoma is surgery, with the aim to obtain R0-type resection. Recently, minimally invasive laparoscopic and robotic-assisted were described [1617]. However, this is difficult to be obtained, the texture and appearance of the tumor being similar to that of healthy tissues [18]. Chan, et al. presented five cases, two of them with significant operative morbidity: one with division and reimplantation of the right ureter, blood loss of $3500 \mathrm{ml}$, and the second with bladder injury and $5000 \mathrm{ml}$ blood loss [5]. They reviewed 106 cases of aggressive angiomyxoma and found a $47 \%$ local recurrence rate, $71 \%$ of recurrences occurring during the first three years [5]. Han-Geurts, et al. reviewed their experience of seven patients with aggressive angiomyxoma, three being pregnant at the time of diagnosis [12]. They questioned the benefits of radical surgery, which did not seem to significantly reduce the recurrence rate when compared to R1 resections [12]. Sozutek, et al. presented a case of giant aggressive angiomyxoma of the pelvis misdiagnosed as incarcerated femoral hernia [19]. Our case had a similar extension of the pelvic tumor through the femoral ring into the femoral area. Sanfilippo, et al. presented a multicenter retrospective analysis of 31 patients with aggressive angiomyxoma [20]. Twenty-nine patients had at least one surgical resection (nine R2-type). The two-year local recurrence rate in patients with R0/R1 resection was $21 \%$. Thirty-five percent of patients received hormonal therapy, which was able to obtain the complete response in a subset of patients and disease control in all cases [20].

Hormonal therapy, including tamoxifen, raloxifene, and gonadotropin-releasing hormone (GnRH) may be useful to downsize the tumor preoperatively or as adjuvant therapy [21]. On the other hand, prolonged GnRH treatment in these young patients is associated with significant osteoporosis or depression [22].

The effectiveness of radiotherapy and chemotherapy as adjuvant therapy to control local recurrences is unclear, due to the low mitotic activity [23].

\section{Conclusions}

Aggressive angiomyxoma is a benign stromal tumor with the capacity to invade adjacent structures and high rate of local recurrence. Surgery represents the mainstay of treatment; however, it should be done with minimal morbidity. Adjuvant therapies, such as hormonal suppression therapies, to control local recurrence should be considered. 


\section{Additional Information \\ Disclosures}

Conflicts of interest: In compliance with the ICMJE uniform disclosure form, all authors declare the following: Payment/services info: All authors have declared that no financial support was received from any organization for the submitted work. Financial relationships: All authors have declared that they have no financial relationships at present or within the previous three years with any organizations that might have an interest in the submitted work. Other relationships: All authors have declared that there are no other relationships or activities that could appear to have influenced the submitted work.

\section{References}

1. Pathology and Genetics of Tumours of Soft Tissue and Bone (World Health Organization Classification of Tumours ). Fletcher CDM, Unni KK, Mertens F (ed): IARC Press, Lyon; 2002.

2. Giles DL, Liu PT, Lidner TK, et al.: Treatment of aggressive angiomyxoma with aromatase inhibitor prior to surgical resection. Int J Gynecol Cancer. 2008, 18:375-379. 10.1111/j.15251438.2007.01005.x

3. Abu JI, Bamford WM, Malin G, et al.: Aggressive angiomyxoma of the perineum. Int J Gynecol Cancer. 2005, 15:1097-1100. 10.1111/j.1525-1438.2005.00182.x

4. Sutton BJ, Laudadio J: Aggressive angiomyxoma. Arch Pathol Lab Med. 2012, 136:217-221. 10.5858/arpa.2011-0056-RS

5. Chan IM, Hon E, Ngai SW, et al.: Aggressive angiomyxoma in females: is radical resection the only option?. Acta Obstet Gynecol Scand. 2000, 79:216-220. 10.1034/j.16000412.2000.079003216.x

6. Rhomberg W, Jasarevic Z, Alton R, et al.: Aggressive angiomyxoma: irradiation for recurrent disease. Strahlenther Onkol. 2000, 176:324-326. 10.1007/s000660050015

7. RAMI International Section Meeting held on 31st January 2015 . Ir J Med Sci. 2015, 184:249344. 10.1007/s11845-015-1321-6

8. Woods SDS, Essex WB, Hughes ESR, et al.: Aggressive angiomyxoma of the female pelvis . Aust N Z J Surg. 1987, 57:687-688. 10.1111/j.1445-2197.1987.tb01450.x

9. Rawlinson NJ, West WW, Nelson M, et al.: Aggressive angiomyxoma with t(12;21) and HMGA2 rearrangement: report of a case and review of the literature. Cancer Genet Cytogenet. 2008, 181:119-124. 10.1016/j.cancergencyto.2007.11.008

10. Simo M, Zapata C, Esquius J, et al.: Aggressive angiomyxoma of the female pelvis and perineum. Report of two cases and review of the literature. BJOG Int J Obstet Gynaecol. 1992, 99:925-927. 10.1111/j.1471-0528.1992.tb14446.x

11. Alameda F, Munné A, Baró T, et al.: Vulvar angiomyxoma, aggressive angiomyxoma, and angiomyofibroblastoma: an immunohistochemical and ultrastructural study. Ultrastruct Pathol. 2006, 30:193-205. 10.1080/01913120500520911

12. Han-Geurts IJM, van Geel AN, van Doorn L, et al.: Aggressive angiomyxoma: multimodality treatments can avoid mutilating surgery. Eur J Surg Oncol. 2006, 32:1217-1221. 10.1016/j.ejso.2006.06.008

13. Srinivasan S, Krishnan V, Ali SZ, et al.: "Swirl sign” of aggressive angiomyxoma-a lesser known diagnostic sign. Clin Imaging. 2014, 38:751-754. 10.1016/j.clinimag.2014.04.001

14. Wiser A, Korach J, Gotlieb WH, et al.: Importance of accurate preoperative diagnosis in the management of aggressive angiomyxoma: report of three cases and review of the literature. Abdom Imaging. 2006, 31:383-386. 10.1007/s00261-005-0378-5

15. Benson JC, Gilles S, Sanghvi T, et al.: Aggressive angiomyxoma: case report and review of the literature. Radiol Case Reports. 2016, 11:332-335. 10.1016/j.radcr.2016.10.006

16. Mera Velasco S, Cabello Burgos AJ, Ruiz López M, et al.: Laparoscopic resection of an aggressive pelvic angiomyxoma. (Article in Spanish). Cir Esp. 2010, 88:121-122. 10.1016/j.ciresp.2009.07.006

17. Tyagi V, Dar TI, Durani AM, et al.: Robotic assisted excision of retrovesical angiomyxoma in a male patient. J Min Access Surg. 2014, 10:84-86. 10.4103/0972-9941.129958

18. Nyam DC, Pemberton JH: Large aggressive angiomyxoma of the perineum and pelvis: an 


\section{Cureus}

alternative approach. Report of a case. Dis Colon Rectum. 1998, 41:514-516.

10.1007/BF02235768

19. Sozutek A, Irkorucu O, Reyhan E, et al.: A giant aggressive angiomyxoma of the pelvis misdiagnosed as incarcerated femoral hernia: a case report and review of the literature. Case Rep Surg. 2016, 2016:1-6. 10.1155/2016/9256749

20. Sanfilippo R, Hindi N, Colombo C, et al.: Multicenter retrospective analysis of 31 patients with aggressive angiomyxoma. J Clin Oncol. 2014, 32:10585.

10.1200/jco.2014.32.15_suppl.10585

21. McCluggage WG, Jamieson T, Dobbs SP, et al.: Aggressive angiomyxoma of the vulva: dramatic response to gonadotropin-releasing hormone agonist therapy. Gynecol Oncol. 2006, 100:623-625. 10.1016/j.ygyno.2005.09.033

22. Shinohara N, Nonomura K, Ishikawa S, et al.: Medical management of recurrent aggressive angiomyxoma with gonadotropin-releasing hormone agonist. Int J Urol. 2004, 11:432-435. 10.1111/j.1442-2042.2004.00816.x

23. Lourenço C, Oliveira N, Ramos F, et al.: Aggressive angiomyxoma of the vagina: a case report . Rev Bras Ginecol Obstet. 2013, 35:575-582. 10.1590/S0100-72032013001200008 